\title{
Public Health Nurses and Family Planning
}

\author{
Deborah Oakley, Ph.D., Janice Swanson, R.N., \\ Ph.D., Ingrid Swenson, R.N., Dr.P.H., and \\ Shirley Marcy, R.N., M.S.N.
}

\begin{abstract}
Unintended pregnancy is a health problem that is particularly important in the practice of public health nurses (PHNs). Data from 844 PHNs showed that they were likely to practice in settings that incorporate family planning services and were knowledgeable about specific family planning methods. They favored family planning services and an expanded supportive government role in both family planning and abortion. Since PHNs are an important resource for the community activism required to build the consensus needed to expand these services, a multiple-regression analysis was performed to determine predictors of activism. Political participation was the major predictor for activism on both family planning and abortion.
\end{abstract}

Deborah Oakley is a Professor in the School of Nursing. University of Michigan, Ann Arbor. Michigan. Janice Swanson is Director of Clinical Research. Merritt Peralta Medical Center and a Professor in the St. Mary's Intercollegiate Nursing Program, Oakland, California. Ingrid Swenson is an Associate Professor of Nursing at the University of North Carolina. Chapel Hill. North Carolina. Shirley Marcy, a Family and Women's Health Nurse Practitioner in Portland, Oregon, is retired.

Address correspondence to Deborah Oakley. Ph.D., Center for Nursing Research, School of Nursing, University of Michigan, Ann Arbor, MI 48109-0482.
Although effective contraception and related services are widely available to the 54.1 million women of childbearing age in the United States, each year there are approximately 3.3 million unintended pregnancies, about one-half of the total (Forrest, 1987). Since public health nurses (PHNs) are a major resource whose professional roles include needs identification, program planning, and intervention at both individual and community levels, their involvement in local family planning program activities constitutes an important resource for dealing with the problem of unintended pregnancies.

In the late 1960s and 1970s, when government funding for local public health family planning programs was new, PHNs who were younger, not Catholic, or did not attend church regularly were more knowledgeable than other PHNs and had more favorable attitudes toward family planning (Baluk \& O'Neill, 1980; Darity \& Thibaux, 1969; Fischer, 1979; Hertel, Hendershot, \& Grimm, 1974; Howard, Lawrence, \& Rasile, 1972; Leif \& Payne, 1975; Payne, 1976; Shea et al., 1973; Werley et al., 1973). In studies comparing nurses with other professionals (Baluk \& O'Neill, 1980; Darity \& Thibaux, 1969; Hertel et al., 1974; Leif \& Payne, 1975; Werley et al., 1973), nurses were less supportive of family planning, but the differences may have been due to the different composition of the nurse and other sample groups. For instance, Werley and Ager (1975) found that nurses had less favorable attitudes about family planning than did physicians and social workers, but these differences were largely accounted for by religion, frequency of church attendance, and race. Hertel et al. (1974) did not try to explain why the nurses they studied expressed less support for abortion than did social workers, but their findings that attitudes differed according to denominational traditionalism and frequency of church attendance are consistent with the possibility 
that the groups may have differed in these characteristics. For some time, measures of religious identification have been less powerful predictors of reproductive behaviors (Westoff \& Bumpass, 1973), and it could be expected that public health nurses have been affected by the social diffusion that has occurred in the rest of society.

Today, two-thirds to three-fourths of reproductiveaged women have favorable opinions about the most effective contraceptive methods (Forrest \& Fordyce, 1988), there is widespread support for publicly funded family planning services (Rosoff, 1988), and the majority of Americans favor protecting a woman's right to choose abortion, although the strength of that support depends on the wording of the survey question and the reasons for the abortion (Anonymous, 1989).

These and other social changes, plus the small samples of earlier studies, made it useful to describe PHNs' current knowledge, attitudes. Because of PHNs key community roles, it is also important to document their involvement in family planning activities, and to investigate factors related to their active involvement with family planning as a public policy issue.

The general literature on mobilization for policy activism shows that typically a small group is actively mobilized on policy or political issues (Almond \& Verba, 1963). Many studies have found that the more educated, the more affluent, the middle-aged, and those who belong to civic interest organizations tend to be most actively involved (Baxter, 1977; Milbrath \& Goel, 1977; Verba \& Nie, 1972). Attitudes and familiarity with issues as problems have also been shown to be related to activism (Baxter \& Lansing, 1980; Klein, 1984; McCourt, 1977). Hanley (1983) showed that many of these same variables contribute to explaining nurses' degree of political involvement.

Therefore, this study was designed to describe current knowledge and attitudes about family planning in a large, nationally diverse sample of public health nurses; and to examine whether demographic and professional characteristics, attitudes, familiarity with the topic through knowledge or service delivery involvement, political participation, or advocacy on other social issues would be related to advocacy for family planning as a policy issue.

\section{METHODS}

\section{Measures}

The questionnaire on nurses' involvement in reproductive health (NIRH) was developed from the StorfjellCruise model of public health nursing (Storfjell \& Cruise, 1984). This model recognizes that there are both individual and community, or aggregate, aspects of
PHN practice. Therefore, the study of knowledge, attitudes, and involvement required variables to measure relevant aspects of both aspects of each of these three general topic areas.

To ensure content-valid scales, items for 11 scales were derived from previous work by Archer (1983), Hanley (1987), and Werley and Ager (1975), and from Gallup and Harris polls. No preexisting scale existed for knowledge about individual care and community assessment aspects of PHN practice for family planning or abortion. Therefore, items measuring both types of knowledge were developed, based on Hatcher et al. (1985), and submitted to a panel of 10 expert judges who sorted them into two separate scales. Items on which there was complete agreement on scale assignment, appropriateness for the scope of nursing practice, and the correct answer among four multiple-choice options were retained and assigned to scoring on their respective scales.

In all, the NIRH included 12 scales plus single-item measures of demographic characteristics and political activism on family planning and abortion. Descriptive information about the 12 scales is organized in Table 1 according to whether the scales pertain to individual or aggregate care. Demographic information gathered dealt with age, sex, marital status, race/ethnicity, parity, residence, education, religion, and frequency of attendance at religious services.

\section{Procedure}

A prepilot was conducted to study readability, appropriateness, and content validity, with 25 nurse-practitioners in a health maintenance organization (HMO) in one of the western states. Nurse-practitioners were chosen because of an expected likelihood of special interest and activism on the key variables. As a result of the prepilot, confusing wording was improved and items were revised as necessary. A pilot study was then done of 100 nurse-practitioners who were members of that western state's Nurse Practitioner Association (minus those who had participated in the prepilot), and 100 other nurses from the same HMO.

For the final study, each person whose name came from a state list was sent a questionnaire with a letter from the investigator in (or near) that state. Permission of the appropriate statewide nursing group had been obtained in advance, and this fact was mentioned in the letters. In addition, there was a standard cover letter from the principal investigator (PI). For the national organization sample, the PI's letter was the only cover letter. Questionnaires were returned to the University of North Carolina at Chapel Hill, where data entry and analysis were conducted. A postcard follow-up to those 
TABLE 1. Descriptive Information About Scales

\begin{tabular}{lcll}
\hline Individual/Aggregate & Number of Items & Possible Range & Response Type \\
\hline Individual & 14 & $1-14$ & Multiple choice \\
$\quad \begin{array}{l}\text { Clinical knowledge } \\
\text { Attitude toward client care }\end{array}$ & 6 & $1-7$ & Likert \\
$\begin{array}{l}\text { Attitude toward PHN role in family planning } \\
\text { No. of family planning or abortion services: direct } \\
\quad \text { care involvement }\end{array}$ & 5 & $1-7$ & Likert \\
$\begin{array}{l}\text { No. of family planning or abortion services provided } \\
\text { in work setting }\end{array}$ & 28 & $1-28$ & Yes/no \\
$\begin{array}{l}\text { Aggregate } \\
\text { Community knowledge }\end{array}$ & & $1-28$ & Yes/no \\
$\begin{array}{l}\text { Attitude toward government role in family planning } \\
\text { or abortion }\end{array}$ & 15 & & \\
$\begin{array}{l}\text { Attitude toward pro-choice organizations } \\
\text { Attitude toward pro-life organizations }\end{array}$ & 11 & $1-15$ & Multiple choice \\
$\begin{array}{l}\text { Involvement with family planning or abortion } \\
\text { organizations }\end{array}$ & 7 & $1-7$ & Likert \\
$\begin{array}{l}\text { Political participation } \\
\text { Social advocacy participation }\end{array}$ & 5 & $1-7$ & Likert \\
\hline
\end{tabular}

who had not responded was sent approximately four weeks after the first questionnaire, and a second questionnaire was sent to those who had not responded by the eighth week.

\section{Sample}

Self-administered questionnaires were mailed to a total of 1900 public health nurses. Two hundred were randomly selected from health department or community health nursing lists in each of five states (two in the northwest, and one each in the southeast, south central, north central regions). Lists were obtained from state officials in government, nursing administrators' groups, or the state nurses' association. All lists were all inclusive. In addition, 900 nurses belonging to a national PHN professional association were sent questionnaires. The state sample was intended to provide information primarily from staff nurses; the national sample was intended to provide information from a cohort that included more public health administrators and educators.

A total of 844 completed, usable questionnaires were included in the analysis ( 395 from the five state samples and 449 from the national organization sample); 55 returned questionnaires were not included because the respondents refused to provide answers, indicated that they could not answer the questions, or were not practicing nursing. Seven questionnaires were returned after data analysis was completed. Thus, the total response rate was $47.6 \%$, although the questionnaires used in the analysis reported here represented $45 \%$ of the total pop- ulation sampled. This response rate is comparable to expectations for return of mailed questionnaires (Kerlinger, 1975).

More than half $(58 \%)$ of the respondents were 30 years of age or older; $85 \%$ were or had been married; $73 \%$ had at least one child; $45 \%$ lived in a town with fewer than 50,000 residents, and $36 \%$ lived in cities of more than 100,000 . Eighty-four percent were white; $99 \%$ were women. Seventeen percent reported that their highest educational preparation was a diploma or associate degree; $37 \%$ had a baccalaureate, $29 \%$ a master's degree, and $8 \%$ a doctoral degree. In the modal group, $55 \%$ were Protestant, $26 \%$ were Catholic, $8 \%$ were affiliated with other religious groups, and the remaining $11 \%$ stated that they identified with no religion. Eightythree percent attended church at least once a month. Sixty-one percent practiced in health departments and worked with adult men and women in their reproductive years.

\section{RESULTS}

Of the 29 knowledge items ( 14 dealing with clinical care of individuals, 15 with community assessment), 17 were answered correctly, as designated by Hatcher et al. (1985) and confirmed by the panel of experts, by a majority of the respondents. The mean number of correct items was 8.0 on the individual scale and 7.4 on the community scale. Questions about birth control techniques and methods were more likely to be correctly answered than were items on specific individual care or community assessment. 
TABLE 2. Percentage Who Had Heard of, Approved, or Supported/Participated in Pro-Choice and Pro-Life Organizations

\begin{tabular}{llll}
\hline Organization & Heard of & Approved (\% Nurses) & Supported/Participated \\
\hline Pro-choice & & & \\
Alan Guttmacher Inst. & 48.2 & 29.7 & 4.9 \\
Center for Population Options & 30.3 & 10.0 & 1.2 \\
National Abortion Rights Action League & 59.7 & 28.6 & 9.6 \\
(NARAL) & & & \\
National Family Planning \& Reproductive Health & 54.8 & 37.7 & 9.6 \\
$\quad$ Association (NFPRHA) & & & \\
Planned Parenthood & 93.4 & 77.8 & 21.9 \\
Local & 93.4 & 78.3 & 16.8 \\
$\quad$ National & 32.1 & 6.4 & 0.2 \\
Population Reference Bureau & 77.3 & 31.2 & 2.1 \\
Zero Population Growth (ZPG) & & & \\
Pro-life & 27.7 & 2.2 & 0.3 \\
American Life Lobby & 36.4 & 7.7 & 1.8 \\
Christian Action Council & 54.8 & 9.7 & 2.4 \\
March for Life & 93.7 & 12.4 & 2.9 \\
National Right to Life Committee & 83.4 & 12.0 & 2.8 \\
Pro-Life Action League & & & \\
\hline
\end{tabular}

Attitudes about client care and about the government role in birth control services were measured with two separate seven-point scales that ranged from 1, strongly disagree, to 7 , strongly agree. The mean scores were 6.2 and 5.3 , respectively. The majority of respondents were supportive of family planning care for individuals and favored a positive government role.

Involvement with family planning was measured in two ways: providing services themselves, and involvement with pro-choice and pro-life organizations. Data not presented in the tables indicated that a large majority of the respondents worked in settings where contraceptive clinical services $(73 \%)$ or sexually transmitted disease (STD) treatment (86\%) were offered, but few worked in settings where abortion was performed $(0.8 \%-4 \%$, depending on the trimester $)$. However, abortion counseling, including options to abortion, was offered in the work settings of $69 \%$ of the respondents. Most said they made referrals for contraception (78\%) and STD treatment $(74 \%)$, and almost as many $(70 \%)$ provided contraceptive education and counseling. Only $22 \%$ actually provided contraceptive clinical services, and virtually no respondent was involved directly in providing abortion services. Most of the major prochoice and pro-life organizations were known to the majority of respondents, but active participation or support was relatively limited (Table 2).

Since research on other topics suggests that activism is related to a general tendency toward mobilization, it was important to examine the level of political participation and activism on related social topics. The majority of PHNs surveyed said they voted in local, state, and
TABLE 3. Percentage Participating in Political Activities

\begin{tabular}{ll}
\hline Political Activity & Participation (\%) \\
\hline Vote in national elections & 96.7 \\
Vote in state elections & 95.8 \\
Vote in local elections & 93.1 \\
$\begin{array}{l}\text { Sign issue petitions } \\
\text { Work with others on community }\end{array}$ & 49.1 \\
$\begin{array}{l}\text { problems } \\
\text { Engage in political discussions }\end{array}$ & 48.5 \\
$\begin{array}{l}\text { Sign petitions to nominate } \\
\text { candidates }\end{array}$ & 40.8 \\
$\begin{array}{l}\text { Form a group to work on local } \\
\text { problems }\end{array}$ & 28.8 \\
$\begin{array}{l}\text { Give money to party or candidate } \\
\text { Protest vigorously if government } \\
\text { does something morally wrong }\end{array}$ & 25.5 \\
$\begin{array}{l}\text { Actively work for party of } \\
\text { candidate }\end{array}$ & 15.3 \\
$\begin{array}{l}\text { Belong to N-CAP } \\
\text { Attempt to persuade others how to } \\
\text { vote }\end{array}$ & 10.7 \\
Attend political meetings, rallies & 9.2 \\
\hline
\end{tabular}

national elections (Table 3). More than half had signed issue petitions, and almost half had engaged in political discussions. At least one-third had contributed money to a party or a candidate, protested vigorously against government action they felt was wrong, or worked with others on community problems, but only about 1 in 10 had actively worked in the political process.

Data not presented in the tables indicate that activism 
on specific issues varied. For example, $53 \%$ were active on behalf of child welfare, $40 \%$ were involved in women's rights, and $39 \%$ in environmental protection. Fewer were involved in civil rights $(30 \%)$, limiting population growth $(23 \%)$, and disarmament $(21 \%)$.

Finally, respondents were asked about their activities in support of both family planning and abortion as policy issues. As shown in Table 4, about one-half had been involved in some activity. Seventeen percent indicated that they had voted for candidates for public office primarily because of their stand on family planning, and slightly more had taken the same action primarily because of candidates' stand on abortion.

The ultimate interest of this study was in discovering predictors of active policy involvement on family planning and abortion. Respondents who had lobbied, written letters, urged others to write or lobby, or voted for candidates based on their stand on these issues were differentiated from those who had actually done none of these actions by creating a dummy variable. Those who were active in one of the four ways were placed in one group, and all the others in the other group. The stepwise multiple-regression results are presented separately for activism about family planning and about abortion in Table 5 . For each, the independent variables

TABLE 4. Percentage Actively Promoting Legislation or Administrative Regulations about Family Planning or Abortion

\begin{tabular}{lcc}
\hline Activity & $\begin{array}{l}\text { Family Planning } \\
(\%)\end{array}$ & $\begin{array}{l}\text { Abortion } \\
(\%)\end{array}$ \\
\hline Lobbied & 5.1 & 3.1 \\
Wrote letters & 22.3 & 16.1 \\
$\begin{array}{l}\text { Urged others to write or } \\
\text { lobby }\end{array}$ & 4.0 & 4.3 \\
$\begin{array}{l}\text { Voted because of } \\
\text { candidate's stand }\end{array}$ & 16.7 & 20.7 \\
$\begin{array}{l}\text { Thought about writing } \\
\text { letters* }\end{array}$ & 10.7 & 10.8 \\
None of the above* & 41.0 & 45.0 \\
\hline
\end{tabular}

*Combined as not activist for the multiple regression. in the study (12 scales plus 9 demographic identifiers) were reduced to a total of 10 by eliminating variables that did not indicate significant bivariate relationships. Three variables entered the regression equation at the 0.05 level of significance for family planning, and two for abortion. The variables that contributed significantly to the regression equation predicted $24 \%$ of the variance in policy activism about family planning, and $19 \%$ of the variance in policy activism about abortion. For both, political participation predicted almost all of the variance that could be explained by the equation as a whole.

\section{DISCUSSION}

The results of this study show that personal involvement in delivering, administering, or at least working in agencies that offer family planning services is widespread among the PHNs studied. The majority favor both individual family planning care and government participation in funding and providing such care.

The overwhelming contribution of political participation to the overall predictive power of the sets of variables considered in this study suggests that policy activism on the two issues are elements of a larger tendency toward political activism. The results underscore that neither concern is isolated, out of the political mainstream. Of the variables measured, political participation in general was the best single predictor of policy activism on both family planning and abortion.

This study focused on individual policy-related action by community health nurses. The next step in effective program building, as the Storfjell-Cruise model suggests, is to develop plans to meet community needs. Public health nurses' readiness and experience can be used to help assess both individual and community needs for family planning programs and services. For instance, many adolescents and poor or near-poor women are still in need of clinical services. Some communities still treat family planning as a taboo subject.

The PHNs can use both their formal and their informal roles to start and aid program development in fam-

TABLE 5. Significant Predictors in Final Multiple-Regression Models of Activism about Family Planning and Abortion

\begin{tabular}{|c|c|c|c|c|c|c|}
\hline Variable & Partial $\mathbf{r}$ & $r^{2}$ & $\mathrm{r}^{2}$ Change & $d f$ & $\mathrm{~F}$ & $P$ \\
\hline \multicolumn{7}{|l|}{ Family planning } \\
\hline Political participation & 0.055 & 0.221 & 0.221 & $8 / 739$ & 52.31 & $<0.001$ \\
\hline Involvement in interest groups & 0.009 & 0.230 & 0.009 & $9 / 738$ & 8.94 & 0.003 \\
\hline Advocacy activism & 0.007 & 0.237 & 0.007 & $10 / 737$ & 7.17 & 0.008 \\
\hline \multicolumn{7}{|l|}{ Abortion } \\
\hline Political participation & 0.044 & 0.186 & 0.186 & $9 / 734$ & 40.05 & $<0.001$ \\
\hline Clinical knowledge & 0.006 & 0.192 & 0.006 & $9 / 734$ & 5.78 & 0.017 \\
\hline
\end{tabular}


ily planning, including the assessment, program planning, program implementation, and evaluation that must be done. Nurses can be particularly helpful in gaining access to and maintaining data systems that include baseline data, appropriate indicators of change, continuous monitoring, and identification of needs that have not yet been taken care of. They are also especially skilled in making specific, realistic proposals for action and influencing public policy makers.

The PHNs can be considered an underused resource in instigating and leading community action. If further gains are to be made in the field of family planning, they have an important role.

\section{ACKNOWLEDGMENT}

This study was partially funded by research grants from Delta Alpha Chapter, Sigma Theta Tau, and from Sigma Theta Tau International. Additional support was provided by the University of North Carolina's Population Center and by the Biomedical Research Support Grant to the University of Michigan School of Nursing.

\section{REFERENCES}

Almond, G. A., \& Verba, S. (1963). The civic culture. Princeton: Princeton University Press.

Anonymous. (1989). Digest: Majority of Americans oppose overturning Roe v. Wade and banning abortion outright, polls show. Family Planning Perspectives, 2/(3), 138-139.

Archer, S. E. (1983). A study of nurse administrators political participation. Western Journal of Nursing Research, 5(1), 65-75.

Baluk, U., \& O'Neill, P. 1980). Health professionals' perceptions of the psychosocial consequences of abortion. American Journal of Community Psychology, 8(1), 67-75.

Baxter, S. K. (1977). Women and politics: The parties, the League of Women Voters and the electorate. Doctoral dissertation, University of Michigan, Ann Arbor.

Baxter, S. K., \& Lansing, M. (1980). Women and politics: The invisible majority. Ann Arbor: University of Michigan Press.

Darity, W. A., \& Thiebaux, J. J. (1969). A study of professional health personnel: An inquiry into barriers to family planning. Advances in Planned Parenthood, 5, 43-57.

Fischer, E. H. (1979). Student nurses view an abortion client: Attitude and context effects. Journal of Population, 2(1), $33-46$.

Forrest, J. D. (1987). Unintended pregnancy among American women. Family Planning Perspectives, 19, 76-80.

Forrest, J. D., \& Fordyce, R. R. (1988). U.S. women's contraceptive attitudes and practice: How have they changed in the 1980s? Family Planning Perspectives, 20(3), 112118.

Hanley, B. E. (1983). Nurse political participation: An in depth view and comparison with women teachers and engineers. Doctoral dissertation, University of Michigan, Ann Arbor.

Hanley, B. E. (1987). Political participation: How do nurses compare with other professional women? Nursing Economics, 5(4), 179-185.

Hatcher, R., Guest, F., Stewart, F., Stewart, G. K., Trussell, J., \& Frank, E. (1985). Contraceptive technology. New York: Irvington Publishers.

Hertel, B., Hendershot, G. E., \& Grimm, J. W. (1974). Religion and attitudes toward abortion: A study of nurses and social workers. Journal for the Scientific Study of Religion, January, 23-34.

Howard, J., Lawrence, J., \& Rasile, K. (1972). A survey of public health nurses' knowledge and attitudes about family planning. American Journal of Public Health, 62, 962-968.

Kerlinger, R. N. (1975). Foundations of behavioral research (2nd ed.). New York; Holt, Rinehart.

Klein, E. (1984). Gender politics. Cambridge: Harvard University Press.

Lief, H., \& Payne. T. (1975). Sexuality: Knowledge and attitudes. American Journal of Nursing, 75(11), 2027-2029.

McCourt, K. (1977). Working-class women and grass-roots politics. Bloomington: Indiana University Press.

Milbrath, L. W., \& Goel, M. L. (1977). Political participation. Chicago: Rand McNally.

Payne, T. (1976). Sexuality of nurses: Correlations of knowledge, attitudes, and behavior. Nursing Research, 25(4), 286-292.

Rosoff, J. I. (1988). The politics of birth control. Family Planning Perspectives, 20(6), 312-320, 297.

Shea, F. P., Werley, H. H., Rosen, R. A. H., \& Ager, J. W. (1973). Survey of health professionals regarding family planning: Preliminary report on nursing students and faculty. Nursing Research, 22(1), 17-24.

Storfjell, J., \& Cruise. P. (1984). A model of communityfocused nursing. Public Health Nursing I(2), 85-96.

Verba, S., \& Nie, N. H. (1972). Participation in America. New York: Harper \& Row.

Werley, H. H., \& Ager, J. (1975). Survey of health professionals regarding family planning. Report prepared for the Bureau for Health Manpower, Chicago, IL: University of Illinois College of Nursing.

Werley, H. H., Ager, J. W., Rosen, R. A. H., \& Shea, F. P. (1973). Medicine, nursing, social work professionals and birth control: Student and faculty attitudes. Family Planning Perspectives, 5(1), 42-49.

Westoff, C. F., \& Bumpass, L. (1973). The revolution in birth control practices of U.S. Roman Catholics. Science, 179, $41-44$. 